\title{
Human Vaccines and Herpes Zoster Ophthalmicus: Clinical Manifestation, Treatment, and Prevention
}

\author{
Vina Yuwanda* \\ Department of Ophthalmology, Murni Teguh Hospital, Medan, North Sumatera, Indonesia
}

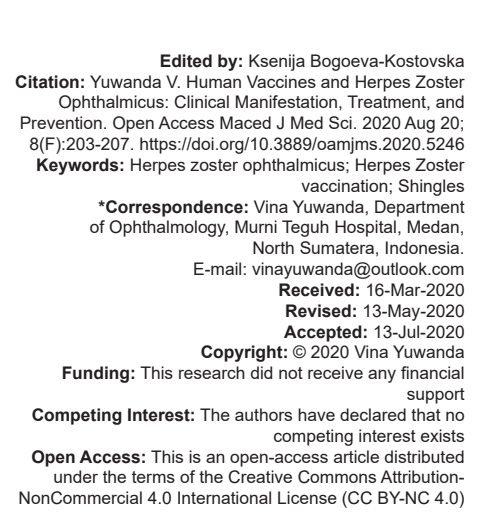

\begin{abstract}
Herpes zoster ophthalmicus $(\mathrm{HZO})$ is a reactivation of $\mathrm{HZ}$ virus that is latent in ophthalmic division of trigeminal ganglion. Patients over 50 years old, premature infant, pregnancy woman, receiving immunosuppressive agents, and malignancies are at risk of having $\mathrm{HZO}$. Ocular manifestations of $\mathrm{HZ}$ are ectropion, entropion, ectopic eyelash, keratitis, conjunctivitis, symblepharon, hypoesthesia, episcleritis, scleritis, scleral atrophy and thinning, uveitis, iris atrophy, posterior synechiae, acute retinal necrosis, progressive outer retinal necrosis, retinal detachment, retina atrophy, optic neuritis, optic atrophy, and strabismus. Polymerase chain reaction, antigen detection, and antibody detection can help to confirm diagnosis. Pharmacology treatments for $\mathrm{HZ}$ ophthalmicus are antiviral drugs, corticosteroids, analgesics, tricyclic antidepressants, and antiepileptic drug. Non-pharmacology therapies are sclera contact lens, phototherapeutic keratectomy, photorefractive keratectomy, and penetrating keratoplasty. There are two kinds of vaccination which can be given to patients: Live-attenuated varicella zoster vaccine and recombinant zoster vaccine. It is recommended by Centers for Disease Control and Prevention and Food and Drugs Administration to use recombinant zoster vaccine by 50 years old.
\end{abstract}

\section{Introduction}

Varicella zoster virus (VZV) is a double-stranded DNA from alpha-herpesvirinae that causes varicella as primary infection and herpes zoster $(\mathrm{HZ})$ after reactivation. VZV has three phases of infection; primary infection, clinical quiescence, and reactivation. During the primary infection, VZV is extremely contagious, especially in children. Virus spreads by direct contact and airborne. It goes to regional lymph nodes to replicate, and primary viremia spreads virus and leads to replication in liver and spleen. Secondary viremia happens when the infected mononuclear cells transfer the virus to skin, which causes swelling of epithelial cells, ballooning degeneration, and accumulation of tissue fluids result in pruritic vesicle formation. The vesicles are mostly on the trunk, head, and face. The rash lasts for 5 days. Other symptoms are malaise, fever, and fatigue [1], [2]

After the primary infection, VZV stays latent in peripheral autonomic ganglia along the entire neuroaxis including dorsal root ganglia, cranial nerve ganglia, and autonomic ganglia. Individuals with older age and impaired cell-mediated immunity are at risk of developing $\mathrm{HZ}$ [3]. $\mathrm{HZ}$ is characterized by severe pain vesicles over the area of skin or mucosa along its dermatomal distribution [1].
Patients with age over 50, premature infants, pregnant woman, HIV infection, using immunosuppressive agents, or certain malignancies and lymphoproliferative disorders are at risk of $\mathrm{HZ}$ reactivation [4]. It is all related to decreasing of VZVspecific cell-mediated immunity. Older age tends to have lower cell-mediated immunity [5].

$\mathrm{HZ}$ ophthalmicus $(\mathrm{HZO})$ is a reactivation of $\mathrm{HZ}$ virus that is latent in the ophthalmic division of trigeminal sensory ganglion, which is separated into nasociliary, frontal, and lacrimal branches. Most of the patients with $\mathrm{HZO}$ present with keratitis, uveitis, and conjunctivitis [6]. Complications of it include glaucoma, corneal scarring, and post-herpetic neuralgia (PHN) that may affect visual function [7].

\section{Epidemiology}

In the United States population, the Centers for Disease Control and Prevention (CDC) estimates that every year there will be 1 million cases of $\mathrm{HZ}$. Other individual studies have varied rates ranging from 3.2 to $4.2 / 1000$ population per year [3]. In Indonesia, there were 2232 herpes zoster patients in 13 training 
hospitals in 2011-2013 with peak age of $\mathrm{HZ}$ around 45-64 years old about $37.95 \%$ of $\mathrm{HZ}$ total case. Women have a higher incidence of having $\mathrm{HZ}$. Incidence of $\mathrm{HZO}$ in dermatology and venereology department of Prof. Dr. R.D. Kandou Hospital in Manado for 20082013 is $17.41 \%$ and has the same incidence for the right and left eye, with the highest incidence of age about 45-64 years (48\%) [4].

\section{$\mathrm{HZO}$}

Patient with HZO mostly has fever, malaise, headache, and neuropathic pain in the eye before skin eruptions happen. Neuropathic pain is described as burning, tingling, or shooting type on the dermatome of infected nerve [5]. Skin lesions erupt on the dermatome of the first division of trigeminal nerve, mostly frontal nerve. Hutchinson's sign is papulovesicular rash at the tip, side or root of nose, which is a clinical sign of $\mathrm{HZO}$ [6]. New lesions keep emerging for 3-5 days, starts with erythema, macules, papules, and vesicles. In elderly or immunocompromised patients, necrotic skin lesions can be found [8]. Skin lesions in zoster can get into deep dermis so that the scar can last for a long time [6]. There is possibility of absence of cutaneous involvement which is called zoster sine herpete [9].

Ocular manifestations of $\mathrm{HZO}$ may involve eyelid, cornea, conjunctiva, episclera, sclera, uvea, optic nerve, oculomotor nerve, trochlear nerve, trigeminal nerve, and abducens nerve. About $80 \%$ of patients with Hutchinson's sign have ocular manifestations [8].

Skin eruptions on eyelid can provoke cicatricial eyelid to ectropion, entropion, or ectopic eyelashes. The complications can be exposure keratopathy and corneal irritation. Complications can be worsen if there are impaired corneal sensation and inadequate tear production [6]. HZ lesions are contagious when there are erupting lesions and before crusts formed [1]. Secondary bacterial cellulitis also occur from Grampositive organism [10].

Corneal complications of $\mathrm{HZO}$ are punctate epithelial keratitis, pseudodendrites ulcers, nummular keratitis, endotheliitis, disciform keratitis, epithelial keratopathy, neurotrophic keratitis, and exposure keratitis [9]. The most often corneal complications of $\mathrm{HZO}$ are punctate epithelial keratitis and pseudodendrites. Both are found to be the earliest and transient sign. Punctate epithelial keratitis with swollen epithelial cells occurs in response to active viral replication. Pseudodendrite is a heap of epithelial cells, raised and edematous epithelial lesions with negative fluorescein staining because the fluorescein gather around the sides of heaped epithelium. The differences from dendrite of herpes simplex are smaller in size, more superficial ulcer, and no terminal bulb
[8]. In nummular keratitis, anterior stromal infiltrates under Bowman's layer in response to immunologic response of viral infection. Endotheliitis presents with diffuse or localized folds of Descemet's membrane, stromal, and epithelial edema. Disciform keratitis presents with multiple areas of corneal edema with minimal infiltration and intact overlying epithelium [10]. Serpiginous keratitis is a peripheral ulcerative keratitis with infiltrations and thinning that can cause perforation or neovascularization. Epithelial keratopathy presents as migrating mucoid plug with variable size and location. It is associated with peripheral interstitial keratitis and/or chronic anterior uveitis. Pathogenesis could be because of low-grade viral replication, immune reactions, or neurotrophic mechanism. Neurotrophic keratopathy has neuronal axonal damage where VZV replicates. Its characteristic is corneal hypoesthesia and appear 3 days after onset of rash, follows with epithelial cicatrization, then causes corneal abnormalities with vascularization and perforation [8].

Conjunctiva is also affected by VZV, it can become simple papillary or follicular conjunctivitis and pseudomembrane cicatrizing conjunctivitis [8]. Afterward, it causes symblepharon and hypoesthesia [9].

Episcleritis and scleritis can occur soon after skin eruptions. In scleritis, patient will feel pain and there will be diffuse or nodular anterior or even necrotizing. In chronic or severe scleritis, there is atrophy and thinning of sclera [8].

Uveitis is a granulomatous or nongranulomatous inflammation of anterior chamber with keratic precipitates, posterior synechiae, and stromal edema. Trabeculitis, trabecular meshwork blockage by cellular debris, hypopyon, pigment or blood, pupillary block by posterior synechiae, or extensive peripheral anterior synechiae can cause hypertony and glaucoma. Ischemic occlusive vasculitis can cause iritis and become sectorial iris atrophy and paralytic mydriasis [8].

Varicella zoster causes acute retinal necrosis (ARN) and progressive outer retinal necrosis (PORN). $A R N$ is diagnosed in the presence of one or more clearly defined foci of retinal necrosis in retinal peripheral, rapid progression of disease without antiviral treatment surrounding peripheral region, occlusive vasculitis with arteritis, and inflammation on anterior and posterior segment. Persistent setting can cause cystoid macular edema, rhegmatogenous retinal detachment, and retina atrophy. ARN is mostly found in immunocompetent patients and PORN in immunosuppressed patients [10].

Infection on optic nerve causes optic neuritis and papillitis, which will lead to optic atrophy. VZV vaccination in immunocompromised patient can cause optic neuritis in few cases. Additional assessments such as MRI of brain and orbit with fat-suppressed sequences are needed to evaluate optic nerve changes. Polymerase chain reaction (PCR) and serology can be obtained on samples of serum and cerebrospinal fluid in 
optic neuropathy or intraocular fluid in uveitis to confirm the diagnosis of $\mathrm{HZ}$ [11].

Ophthalmoplegia can be originated from neurological or orbital lesions and cause internuclear ophthalmoplegia, strabismus, isolated, or combined ocular motor cranial nerve palsy and orbital myositis. Ptosis and lagophthalmus are also likely to happen when cranial nerves are infected. When VZV infects oculomotor, trochlear, and abducens nerve, there will be paralysis of eye movement. Long-term effect will cause strabismus. Patients with ophthalmoplegia needed to acquire contrast-enhanced MRI of brain and orbits. MRI orbital of patients with proptosis, ptosis, chemosis, and ophthalmoplegia will show enlargement of extraocular muscle and enhancement of extraocular muscle, orbital soft tissue, lacrimal gland, and optic nerve sheath. If there are meningeal enhancement, ischemic stroke, or vasculopathy, lumbar puncture should be performed to confirm VZV infection [11].

Most common complication of $\mathrm{HZ}$ is $\mathrm{PHN}$. Some authors consider post-herpetic neuralgia if the pain persists at least 90 days after the onset or resolution of rash [12]. Pain varies from allodynia, electric shock, stinging, itching, and burning. Risk of PHN increased by older age, extension, and severity of rash and early neuralgia and decline sensitivity of skin and cornea. Pathogenesis of PHN is not clear yet, it can be caused by chronic inflammation in trigeminal pathway after acute infection resolved. Low-grade viral replication can be happened during chronic inflammation [8].

Diagnosis of $\mathrm{HZ}$ is decided based on history, clinical, and laboratory test if needed. Laboratory test is needed when there is diagnostic uncertainty. Laboratory test can be done by PCR, antigen detection, antibody detection, and viral culture. PCR as the most sensitive method has $95-100 \%$ of sensitivity and specificity. The sample can be obtained from vesicle fluid, moistened swab on dried lesion or lesion crusts, salivary fluid, biopsy, cerebrospinal fluid, intraocular fluid, and blood samples. Antigen of VZV proteins is detected by direct fluorescent antibody (DFA) or immunohistochemistry (IHC). Sensitivity and specificity of DFA are $82-98 \%$ and $76-94 \%$. IHC has $100 \%$ specificity and $94.9 \%$ using anti-glycoprotein $E$. Serology detection of $\operatorname{lgM}$, lgG, and $\lg A$ of VZV by ELISA, EIA, histochemical staining without $I H C$, electron, and immunogold electron microscopy is recommended for $\mathrm{HZ}$ ophthalmicus. In viral culture, virus is isolated on human diploid lung fibroblast (W-38 or MRC-5) or human retinal pigment epithelial cells. Viral culture is needed to know drug sensitivity or molecular characterization [13].

\section{Treatment}

The aims of $\mathrm{HZ}$ treatment are lowering viral replication, accelerating healing, limiting severity, managing acute pain, and reducing complications. Antiviral drugs, corticosteroids, and analgesic are used for this treatment. Treatment is recommended started within 3 days after rash onset. Encrusted lesions are less likely to have benefit of antiviral therapy. Patients with $\mathrm{HZ}$ need to have extra rest, stay hydrated, and eat balanced nutrition foods to improve the immune system. 8

Acyclovir as the first antiviral drug effective against VZV, inhibits viral DNA polymerase to inhibit VZV replication. Recommended dose of acyclovir is 800 mg orally 5 times daily for 7-10 days. Intravenous (IV) acyclovir is given only for severe $\mathrm{HZO}$ in $10-15 \mathrm{mg} / \mathrm{kg}$ 3 times daily for 7 days. This dosage reduces ocular complications such as dendritic keratitis, stromal keratitis, uveitis, scleritis, and episcleritis [8].

Recommended doses of other ARV are valacyclovir $1000 \mathrm{mg} 3$ times daily and famciclovir 500 mg 3 times daily [8]. In uncomplicated case, they will be given for 7-10 days [5].

Famciclovir and valacyclovir found to be more effective because of better absorption results in higher antiviral activity and less dosing frequency. Patients taking these drugs need to stay hydrated because increased creatinine levels found in poorly hydrated patients. Alcohol should be avoided because of the diuretic effects and interactions with analgesics [14]. Foscarnet can be given as alternative in resistant $\mathrm{HZO}$, dosing $40 \mathrm{mg} / \mathrm{kg} 3$ times a day to $100 \mathrm{mg} / \mathrm{kg}$ twice a day for 14-28 days [9].

In ARN, patient receives acyclovir $10 \mathrm{mg} / \mathrm{kg}$ every $8 \mathrm{~h}$ for 10-14 days, then followed by valacyclovir $1000 \mathrm{mg}$ orally 3 times a day for 6 months. In PORN, patient is given ganciclovir $5 \mathrm{mg} / \mathrm{kg}$ IV every $12 \mathrm{~h}$ and foscarnet $90 \mathrm{mg} / \mathrm{kg}$ IV every $12 \mathrm{~h}$ and intravitreal ganciclovir $2 \mathrm{mg} / 0.05 \mathrm{~mL}$ twice a week and/or intravitreal foscarnet $1.2 \mathrm{mg} / 0.05 \mathrm{~mL}$ twice weekly. In optic neuropathy patients, IV acyclovir $10-15 \mathrm{mg} / \mathrm{kg}$ every $8 \mathrm{~h}$ for 2-3 weeks is recommended [15]. Corticosteroid is recommended only for combination with antiviral drug. It can reduce the pain and increase the rate of cutaneous healing. Dosage of $60 \mathrm{mg} /$ day of systemic corticosteroid is recommended to reduce the pain, then tapered off for 2 weeks to minimize rebound of inflammation [15]. Corticosteroid treatment in cranial neuropathy is given for 5 days. Systemic corticosteroids are also indicated for facial palsy, cranial polyneuritis, and severe inflammatory ocular complications. Topical corticosteroids treat disciform keratitis, endotheliitis, anterior uveitis, and optic neuropathy [5], [16]. However, the use of corticosteroid is controversial because it will increase risk of ocular complications, thinning and perforation of cornea, secondary glaucoma, and reactivated dendriform keratitis [5].

For the treatment of PHN, tricyclic antidepressants, antiepileptic drug, and analgesics are the first-line therapy. Nortriptyline $25 \mathrm{mg}$ at bedtime 
can be added up to $75 \mathrm{mg}$, gabapentin 300-600 mg 3 times a day, and oxycodone 10-20 mg 2 times a day. Applying lidocaine 4\% eye drop lessens the pain on the eye and forehead in $15 \mathrm{~min}$ and persists for $36 \mathrm{~h}$ [15].

Non-pharmacologic treatments such as lateral tarsorrhaphy or lid traction sutures to correct scarring on the lid [14]. Scleral contact lenses may be used in patients with corneal scarring and severe neurotrophic keratopathy to prevent corneal perforation [15], [17]. Phototherapeutic keratectomy and photorefractive keratectomy can be successful if ocular surface is healthy and normal corneal sensation [17]. Penetrating keratoplasty is done for widespread corneal scarring [15].

\section{Prevention}

There are two kinds of VZV vaccines available worldwide, Zostavax (live-attenuated VZV vaccine/ZVL) and Shringlex (recombinant zoster vaccine/RZV). Live zoster vaccine has dropped $\mathrm{HZ}$ incidence by $51 \%$ and post-herpetic neuralgia by $66 \%$ in immunocompetent people with 60 years old and older. However, it will lose its effectivity after 10 years of vaccination. Recombinant zoster vaccine contains VZV glycoprotein E surface antigen conjoint with a novel adjuvant system. A clinical trial was made in adults 50 years old and over, demonstrated that the efficacy of the vaccine was $97 \%$ in all age groups. Another clinical trial for adults 70 years old and over showed $90 \%$ efficacy. It is still effective approximately $85 \%$ after 4 years [18] [19].

Dose of ZVL is 19.400 plaque-forming units of $V Z V$, injected subcutaneously on deltoid region once. ZVL is stored in freezer [20]. Vaccine is given within 30 min after dissolved. Vaccination should be postponed if there is fever over $38.5^{\circ} \mathrm{C}$ [19]. Patients have local adverse reactions such as erythema, swelling, warmth, pruritus, pain, and systemic adverse reactions such as $\mathrm{HZ}$, pain, rash, pyrexia, dyspnea, asthenia, headache, nausea, and dizziness [21].

CDC recommended ZVL given to immunocompetent people 60 years old and older and people with chronic illness that has humoral immunity affected and those anticipating becoming immunocompromised. Meanwhile, Food and Drugs Administration (FDA) recommended to people 50 years old and older because the incidence of $\mathrm{HZ}$ was cut down by $70 \%$ of people with $50-59$ years of age group [18]. Patients who are immunocompromised or receiving immunosuppression treatment are contraindicated to receive vaccination. Immunocompromised patients in this context are patients in primary immunodeficiency history, leukemia, lymphoma, or other malignant neoplasm that affect bone marrow or lymphatic system, or AIDS or HIV with CD-4 titer less than $200 / \mathrm{mm}^{3}$ or $<15 \%$ of total lymphocyte, patients who received high dose of corticosteroid ( $\geq 20 \mathrm{mg} /$ day prednisone or equivalent) for 2 weeks or more, using $>0.4 \mathrm{mg} / \mathrm{kg} /$ week of methotrexate, $>3 \mathrm{mg} / \mathrm{kg} /$ day of azathioprine or $>1.5 \mathrm{mg} / \mathrm{kg} /$ day mercaptopurine, treatment with adalimumab, infliximab, or etanercept and transplantation of hematopoietic stem cell $<2$ years. Pregnancy and active untreated tuberculosis are also contraindicated to have vaccine [4].

Patients can be vaccinated after 1 month of stopping corticosteroid consumption. Patients who receive immunomodulator can be vaccinated after 3 months receiving immunomodulator [18]. $R Z V$ is given two doses with 2-6 months apart intramuscularly [22]. It is stored in refrigerator between $2^{\circ} \mathrm{C}$ and $8^{\circ} \mathrm{C}$. Vaccine can be stored to $6 \mathrm{~h}$ after reconstitution [20]. It must be disposed if frozen before or after reconstitution [22]. There are RZV studies reported local and systemic reactions after vaccination. Local reactions such as pain, redness and swelling, and systemic reactions myalgia, fatigue, headache, shivering, fever, and gastrointestinal symptoms [20]. Acute local and systemic reactions happen more often in people 50-69 years of age than in older than 70 years, and systemic reactions happened more frequently after the second dose than the first dose [22].

FDA and CDC recommended RZV vaccination for immunocompetent adults 50 years old or older, including people who has been vaccinated with ZVL at least 2 months previously. RZV is preferred by CDC over ZVL because higher and longer lasting efficacy across all age groups. Recommendation for immunocompromised patients, pregnant, and nursing woman is not known yet because they were excluded from the clinical trials. Advisory Committee for Immunization Practices and CDC recommend RZV as first-line therapy [18].

\section{References}

1. Kennedy PG, Gershon AA. Clinical features of varicellazoster virus infection. Viruses. 2018;10(11):609. https://doi. org/10.3390/v10110609

PMid:30400213

2. Butel J. Herpesvirus. In: Brooks GF, Carroll KC, Butel JS, Morse SA. Jawetz, Melnick, and Adelberg's Medical Microbiology. $24^{\text {th }}$ ed. America, United States: The McGraw-Hill Companies; 2007. p. 437-40.

3. Tran KD, Falcone MM, Choi DS, Goldhart R, Karp CL, Davis JL, et al. Epidemiology of herpes zoster ophthalmicus: Recurrence and chronicity. Ophthalmology. 2016;123(7):1469-75. https:// doi.org/10.1016/j.ophtha.2016.03.005

PMid:27067924

4. Kelompok Studi Herpes Indonesia. Buku Panduan Herpes Zoster di Indonesia. Jakarta: Badan Penerbit Fakultas Kedokteran Universitas Indonesia; 2014. https://doi. org/10.21009/jrskt.032.07

5. Vrcek I, Choudhury E, Durairaj V. Herpes zoster ophthalmicus: 
A review for the internist. Am J Med. 2017;130(1):21-6. https:// doi.org/10.1016/j.amjmed.2016.08.039

PMid:27644149

6. Liesegang TJ. Herpes zoster ophthalmicus: Natural history, risk factors, clinical presentation, and morbidity. Ophthalmology. 2008;115(2):S3-12. https://doi.org/10.1016/j. ophtha.2007.10.009

PMid: 18243930

7. Shaikh S, Ta CN. Evaluation and management of herpes zoster ophthalmicus. Am Fam Physician. 2002;66(9):1723-30.

PMid:12449270

8. Rousseau A, Bourci T, Colin J, Labetoulle M. Herpes zoster ophthalmicus-diagnosis and management. US Ophthalmic Rev. 2013;6(2):1-6.

9. Bandeira F, Roizenbalt M, Levi GC, Freitas DD, Belfort RJ. Herpes zoster ophthalmicus and varicella zoster virus vasculopathy. Arq Bras Oftalmol. 2016;79(2):126-9. https://doi. org/10.5935/0004-2749.20160038

PMid:27224081

10. Davis AR, Sheppard J. Herpes zoster ophthalmicus review and prevention. Eye Contact Lens. 2019;45(5):286-91. https://doi org/10.1097/icl.0000000000000591

PMid:30844951

11. Kedar S, Jayagopal LN, Berger JR. Neurological and ophthalmological manifestations of varicella zoster virus. J Neuroophthalmol. 2019;39(2):220-31. https://doi.org/10.1097/ wno. 0000000000000721

PMid:30188405

12. Gater A, Uhart M, McCool R, Préaud E. The humanistic, economic and societal burden of herpes zoster in Europe: A critical review. BMC Public Health. 2015;15:193. https://doi. org/10.1186/s12889-015-1514-y

PMid:25880058

13. Werner RN, Nikkels AF, Marinovic B, Schäfer M, CzameckaOperacz M, Agius AM, et al. European consensus-based (S2k) Guideline on the management of herpes zoster guided by the European dermatology forum (EDF) in cooperation with the European Academy of dermatology and venereology (EADV),
Part 1: Diagnosis. J Eur Acad Dermatol Venereol. 2017;31(1):919. https://doi.org/10.1111/jdv.13995 PMid:27804172

14. Reeves G, Beuscher L. Herpes zoster in older adults: An educational approach. J Nurse Pract. 2015;11(5):538-43. https://doi.org/10.1016/j.nurpra.2015.02.003

15. Johnson JL, Amzat R, Martin N. Herpes zoster ophthalmicus. Prim Care. 2015;42(3):285-303.

16. Kaufman AR, Myers EM, Moster ML, Stanley J, Kline LB, Golnik KC, et al. Herpes zoster optic neuropathy. J Neuroophthalmol. 2018;38(2):179-89. https://doi.org/10.1097/ wno. 0000000000000607 PMid:29266031

17. Hassan $\mathrm{OM}$, Farroq $\mathrm{AV}$, Soin $\mathrm{K}$, Djalilian $\mathrm{AR}$, Hou JH, et al. Management of corneal scarring secondary to herpes zoster keratitis. Cornea. 2017;36(8):1018-23. https://doi.org/10.1097/ ico. 0000000000001235 PMid:28582374

18. Lum F. Policy statement recommendations for herpes zoster vaccine for patients 50 years of age and older. Ophthalmology. 2018;125(11):1813-6.

19. Adiwinata R, Suseno E. Role of vaccination in herpes zoster prevention. CDK. 2016;43(6):432-4

20. Maltz F, Fidler B. Shingrix: A new herpes zoster vaccine. P T. 2019;44(7):406-9.

PMid:31258310

21. Miller ER, Lewis P, Shimabukuro TT, Su J, Moro P, Woo EJ, et al. Post-licensure safety surveillance of zoster vaccine live (Zostavax®) in the United States, vaccine adverse event reporting system (VAERS), 2006-2015. Hum Vaccin Immunother. 2018;14(8):1963-9. https://doi.org/10.1080/21645 515.2018 .1456598

PMid:29580194

22. Jeng BH. Herpes zoster eye disease: New ways to combat an old foe? Ophthalmology. 2018;125(11):1671-4. https://doi. org/10.1016/j.ophtha.2018.08.029

PMid:30318036 